\title{
PENGARUH VARIASI KONSENTRASI LARUTAN SERBUK DAUN JERUK PURUT (Citrus hystrix. DC) TERHADAP PARAMETER ANGKA KUMAN PADA PERALATAN MAKAN
}

\author{
Sri Ningrum, Munawar Raharja, Rahmawati \\ Poltekkes Kemenkes Banjarmasin Jurusan Kesehatan Lingkungan \\ Jl. H. Mistar Cokrokusumo No. 1A Banjarbaru Kalimantan Selatan 70714 \\ E-mail: sriningrum21@gmail.com
}

\begin{abstract}
The effect of variation concentration of solution powder kaffir lime leaves (Citrus hystrix. dc) against the parameter of figure germ at eating utensils. The recommended disinfection process such as the use of heat and chemicals in a society generally not done because it takes a long time and expensive cost, as well as the excessive use of chemicals, can cause environmental pollution. Therefore, the necessary natural ingredients as a substitute as kaffir lime leaves. Based on the research results Sulistiyani, et al (2004) showed a rinsing by using kaffir lime leaves can decrease the number of microbes on eating utensils. This study aims to determine the effect of variation concentration of solution powder kaffir lime leaves (Citrus hystrix. DC) against the parameter of figure germ at eating utensils. This type of research is experimental, pretest-posttest design with the control group. The samples used were 42 swab samples plate tools. Methods of data collection based on the check out results from the number of figure germ (TPC) in the laboratory. Analysis of data using statistical test Paired t-test and correlation test. The results showed that the average total number of figure germs before treatment ranged from 44-73 colonies $/ \mathrm{cm}^{2}$, and the average total number of figure germs after disinfection treatment with a solution of powdered kaffir lime leaves ranging between 6-50 colonies $/ \mathrm{cm}^{2}$. Based Paired t-test is known that there are differences the average number of figure germ before and after treatment, where the average total number of figure germs after treatment is lower than the average number of figure germs before treatment with the percentage decrease ranging between $23-89 \%$. Statistical analysis of the correlation test showed there is a relationship between variations in concentration of powder kaffir lime leaves with the number of figure germ on the plate. Kaffir lime leaves contain chemical compounds polyphenols, flavonoids, essential oils, tannins and alkaloids that have a pharmacological effect as an antiseptic, so it can be used as a disinfectant to wash eating utensils.
\end{abstract}

Keywords: Kaffir lime leaves (Citrus hystrix. DC); figure germs. Abstrak: Pengaruh variasi konsentrasi larutan serbuk daun jeruk purut (Citrus
hystrix. DC) terhadap parameter angka kuman pada peralatan makan. Proses
desinfeksi yang dianjurkan seperti penggunaan suhu panas dan pemberian bahan kimia di
masyarakat umumnya tidak dilakukan, karena membutuhkan waktu yang lama dan biaya
yang mahal, serta penggunaan bahan kimia berlebihan dapat menimbulkan pencemaran
lingkungan. Oleh sebab itu, diperlukan bahan-bahan alami sebagai pengganti seperti daun
jeruk purut. Berdasarkan hasil penelitian Sulistiyani, dkk (2004) menunjukkan bahwa
bilasan dengan menggunakan perasan daun jeruk purut dapat menurunkan jumlah mikroba
pada alat makan. Penelitian ini bertujuan untuk mengetahui pengaruh variasi konsentrasi
larutan serbuk daun jeruk purut (Citrus hystrix. DC) terhadap angka kuman pada peralatan
makan. Jenis penelitian adalah eksperimen, dengan desain Pretest-Posttest Control Group.
Sampel yang digunakan sebanyak 42 sampel usap alat piring. Metode pengumpulan data
berdasarkan hasil pemeriksaan angka kuman (TPC) di laboratorium. Analisis data
menggunakan uji statistik Paired T-test dan uji korelasi. Hasil penelitian menunjukkan
bahwa rata-rata jumlah angka kuman sebelum perlakuan berkisar antara $44-73$ koloni/cm ${ }^{2}$
dan rata-rata jumlah angka kuman sesudah perlakuan desinfeksi dengan larutan serbuk
daun jeruk purut berkisar antara $6-50$ koloni/ $\mathrm{cm}^{2}$. Berdasarkan uji Paired T-test diketahui 
bahwa ada perbedaan rata-rata jumlah angka kuman sebelum dan sesudah perlakuan, dimana rata-rata jumlah angka kuman sesudah perlakuan lebih rendah dibandingkan ratarata jumlah angka kuman sebelum perlakuan dengan prosentase penurunan berkisar antara 23-89\%. Analisis statistik uji korelasi menunjukkan bahwa ada hubungan yang variasi konsentrasi larutan serbuk daun jeruk purut dengan angka kuman pada piring. Daun jeruk purut mengandung senyawa kimia polifenol, flavonoid, minyak atsiri, tanin dan alkaloid yang mempunyai efek farmakologis sebagai antiseptik, sehingga dapat digunakan sebagai desinfektan pencucian peralatan makan.

Kata Kunci: Daun jeruk purut (Citrus hystrix. DC); angka kuman.

\section{PENDAHULUAN}

Macam sumber kontaminasi

potensial pada makanan yang dapat menyebabkan penyakit akibat bawaan makanan dipengaruhi oleh beberapa faktor, yaitu faktor tempat, faktor makanan, faktor manusia (orang) serta faktor peralatan pengolahan dan peralatan makanan (UU RI, 2012). Diperkirakan sekitar $80 \%$ penyakit bawaan makanan atau keracunan makanan disebabkan oleh adanya kontaminasi mikroba yang salah satunya berasal dari peralatan yang digunakan [1].

Adapun peralatan yang dapat mengkontaminasi makanan adalah peralatan yang tidak bersih dan yang dalam tahap proses pencuciannya kurang sempurna dan kurang tepat karena tidak melakukan tahapan desinfeksi. Berdasarkan hasil penelitian Agustina Istiqlaliah (2009) tentang kualitas kebersihan peralatan makan pada rumah makan di Agrowisata Bincau Kabupaten Banjar, menunjukkan bahwa tidak ada satupun rumah makan (dari 4 buah sampel rumah makan) yang memenuhi standar kebersihan peralatan makan seperti yang ditetapkan Kepmenkes RI No. 1098 tahun 2003. Angka kuman yang terdapat pada peralatan makan tersebut berkisar antara $110 \mathrm{koloni} / \mathrm{cm}^{2}$ sampai dengan 36.700 koloni koloni/ $\mathrm{cm}^{2}$.

Tingginya angka kuman tersebut berhubungan dengan upaya pemeliharaan kebersihan peralatan makan, yaitu kurang sempurnanya proses pencucian peralatan, menggunakan kain lap yang dipakai berulang-ulang dan tidak dilakukannya proses desinfeksi peralatan yang dicuci.

Terdapat berbagai cara proses desinfeksi peralatan makan yang digunakan, yaitu dengan pemberian bahan kimia (chlor dengan konsentrasi 50-250 ppm) dan penggunaan suhu panas (perebusan dengan suhu $100{ }^{\circ} \mathrm{C}$ selama 1 menit atau dengan suhu $82{ }^{\circ} \mathrm{C}$ selama 2 menit [2]. Di masyarakat proses desinfeksi yang dianjurkan kebanyakan tidak dilakukan karena, apabila dengan cara pemberian bahan kimia chlor memiliki kekurangan dapat menimbulkan bau pada air yang tidak disukai oleh masyarakat dan apabila dengan penggunaan suhu panas dianggap membutuhkan waktu yang lama dan biaya yang mahal.

Penggunaan bahan kimia sebagai bahan desinfeksi secara berlebihan dapat menghasilkan limbah cair yang dapat menimbulkan pencemaran lingkungan akibat penggunaan bahan kimia. Oleh sebab itu, diperlukan bahan-bahan alami dan mudah didapat sebagai pengganti penggunaan bahan desinfektan kimia [3].

Jeruk purut adalah tanaman yang daunnya biasa dimanfaatkan oleh masyarakat sebagai bumbu penyedap masakan dan mudah didapatkan [4]. Di dalam daun jeruk purut memiliki kandungan senyawa kimia alkaloid, polifenol, minyak atsiri, tanin dan flavonoid yang mempunyai efek farmakologis sebagai antiseptik dan mempunyai antioksidan yang sangat tinggi dan bahan-bahan tersebut dapat berfungsi sebagai desinfektan serta bioinsektisida [5].

Pada penelitian Miftahendarwati (2014) yang menggunakan ekstrak daun jeruk purut (Citrus hystrix) dan klorheksidin 2\% sebagai perbandingan efek antibakteri terhadap bakteri Streptococcus mutans dengan konsentrasi 
yang diuji adalah 5\%, 10\%, 15\%, 20\%, $25 \%$ dan metode difusi agar pada media Muller Hinton Agar (MHA) dengan menggunakan larutan uji yaitu klorheksidin $2 \%$ dan ekstrak daun jeruk purut $25 \%$. Hasil penelitian menunjukkan bahwa ekstrak daun jeruk purut 25\% mampu menghambat bakteri Streptococcus mutans.

Hasil penelitian Sulistiyani, dkk (2004), menunjukkan bahwa bilasan dengan menggunakan perasan daun jeruk purut konsentrasi $50 \mathrm{mg} / \mathrm{mL}$ dengan waktu kontak 3 menit dapat menurunkan jumlah mikroba pada alat makan. Didapat hasil rata-rata jumlah mikroba sebelum dicuci dengan perasan daun jeruk purut adalah $13.2 \times 10^{3}$ koloni per $\mathrm{cm}^{2}$ dan ratarata jumlah mikroba setelah dicuci dengan perasan daun jeruk purut adalah $9.7 \times 10^{2}$ koloni per $\mathrm{cm}^{2}$.

Dari penelitian tersebut menunujukkan bahwa daun jeruk purut dapat berfungsi sebagai bahan desinfektan yang mampu menyebabkan enzim-enzim pada bakteri menjadi inaktif dengan konsentrasi $50 \mathrm{mg} / \mathrm{mL}$ selama waktu kontak 3 menit, namun pada konsentrasi tersebut penurunan jumlah mikroba belum dapat memenuhi standar kebersihan peralatan makan yang ditentukan. Maka berdasarkan uraian tersebut peneliti tertarik untuk melakukan penelitian lebih lanjut tentang pengaruh variasi konsentrasi larutan serbuk daun jeruk purut (Citrus hystrix. DC) yang efektif untuk menurunkan jumlah angka kuman pada peralatan makan.

Secara umum tujuan penelitian ini yaitu untuk mengetahui pengaruh variasi konsentrasi larutan serbuk daun jeruk purut (Citrus hystrix. DC) terhadap parameter angka kuman pada peralatan makan, dengan diketahui melihat jumlah angka kuman pada piring sebelum diberi perlakuan dan sesudah diberi perlakuan dengan larutan serbuk daun jeruk purut (Citrus hystrix. DC) pada konsentrasi 50 gr/L, $60 \mathrm{gr} / \mathrm{L}, 70 \mathrm{gr} / \mathrm{L}, 80 \mathrm{gr} / \mathrm{L}, 90 \mathrm{gr} / \mathrm{L}$ dan $100 \mathrm{gr} / \mathrm{L}$.

\section{BAHAN DAN CARA PENELITIAN}

Desain penelitian secara eksperimen, yaitu dengan uji coba menggunakan 6 variasi konsentrasi larutan serbuk daun jeruk purut (Citrus hystrix DC) yaitu $50 \mathrm{gr} / \mathrm{L}, 60 \mathrm{gr} / \mathrm{L}, 70$ gr/L, $80 \mathrm{gr} / \mathrm{L}, 90 \mathrm{gr} / \mathrm{L}$ dan $100 \mathrm{gr} / \mathrm{L}$ sebagai desinfektan peralatan makan.

Populasi penelitian adalah seluruh piring yang digunakan oleh tempat makan Warung Pojok (Warjok) di Jalan Astoria Komplek Citra Persada Asri RT. 17 RW.03 Sungai Besar, Kota Banjarbaru. Sampel yang digunakan adalah sebanyak 42 sampel usap alat dari sekelompok piring (84 buah piring) yang telah digunakan oleh konsumen pada Warung Pojok.

Variabel yang diteliti pada penelitian ini meliputi 2 variabel yaitu variabel independent (bebas) dan variabel dependent (terikat). Untuk variabel independent yang diteliti adalah variasi konsentrasi larutan serbuk daun jeruk purut (Citrus hystrix. DC) yaitu 50 $\mathrm{gr} / \mathrm{L}, 60 \mathrm{gr} / \mathrm{L}, 70 \mathrm{gr} / \mathrm{L}, 80 \mathrm{gr} / \mathrm{L}, 90 \mathrm{gr} / \mathrm{L}$ dan $100 \mathrm{gr} / \mathrm{L}$, sedangkan untuk variabel dependent yang diteliti adalah jumlah angka kuman sebelum dan sesudah diberikan perlakuan desinfeksi. Data diperoleh dengan teknik observasi/ pengamatan menggunakan instrument yaitu lembar observasi (check list) yang diisi berdasarkan hasil pemeriksaan jumlah angka kuman yang didapat setelah dilakukannya uji laboratorium TPC pada sampel peralatan makan

Pengolahan data dianalisis menggunakan uji statistik korelasi untuk mengetahui keeratan hubungan dan arah hubungan pada variasi konsentrasi larutan daun jeruk purut dengan penurunan angka kuman.

\section{HASIL PENELITIAN DAN PEMBAHASAN}

\section{Angka kuman pada piring sebelum} perlakuan

Dari hasil pemeriksaan laboratorium terhadap parameter mikrobiologi yaitu angka kuman usap alat (TPC) pada piring sebelum diberikan perlakuan desinfeksi menggunakan larutan serbuk daun 
jeruk purut (Citrus hystrix. DC) dapat

dilihat pada tabel 1 .

Tabel 1. Angka Kuman (koloni $/ \mathrm{cm}^{2}$ ) pada Piring Sebelum Diberikan Perlakuan Menggunakan Larutan Serbuk Daun Jeruk Purut (Citrus hystrix. DC)

\begin{tabular}{cccccccc}
\hline \multirow{2}{*}{ Ulangan } & \multicolumn{7}{c}{ Kode Piring Sebelum Perlakuan } \\
& 1 & 2 & 3 & 4 & 5 & 6 & 7 \\
\hline 1 & 44 & 43 & 125 & 63 & 90 & 59 & 56 \\
2 & 50 & 66 & 38 & 63 & 51 & 44 & 55 \\
3 & 38 & 59 & 53 & 66 & 79 & 70 & 54 \\
Rata-rata & 44 & 56 & 72 & 64 & 73 & 58 & 55 \\
\hline
\end{tabular}

Berdasarkan tabel 1 dapat diketahui bahwa rata-rata jumlah angka kuman pada usap alat sekelompok piring sebelum diberikan perlakuan pada kode sekelompok piring $1-7$ berkisar antara $44-73$ koloni $/ \mathrm{cm}^{2}$.

\section{Angka kuman pada piring sesudah perlakuan}

Berdasarkan hasil pemeriksaan laboratorium terhadap parameter mikrobiologi yaitu angka kuman usap alat (TPC) pada piring sesudah diberikan perlakuan desinfeksi menggunakan larutan serbuk daun jeruk purut (Citrus hystrix. DC) dengan variasi konsentrasi $0 \mathrm{gr} / \mathrm{L}, 50 \mathrm{gr} / \mathrm{L}, 60$ gr/L, 70 gr/L, 80 gr/L, 90 gr/L dan 100 gr/L pada waktu kontak 3 menit, dapat dilihat pada tabel 2 .

Tabel 2. Angka Kuman (koloni/ $\mathrm{cm}^{2}$ ) pada Piring Sesudah Diberikan Perlakuan Menggunakan Larutan Serbuk Daun Jeruk Purut (Citrus hystrix. DC)

\begin{tabular}{cccccccc}
\hline \multirow{3}{*}{ Ulangan } & $0 \mathrm{gr} / \mathrm{L}$ & $50 \mathrm{gr} / \mathrm{L}$ & $60 \mathrm{gr} / \mathrm{L}$ & $70 \mathrm{gr} / \mathrm{L}$ & $80 \mathrm{gr} / \mathrm{L}$ & $90 \mathrm{gr} / \mathrm{L}$ & $100 \mathrm{gr} / \mathrm{L}$ \\
& $(1)$ & $(2)$ & $(3)$ & $(4)$ & $(5)$ & $(6)$ & $(7)$ \\
\hline 1 & 36 & 35 & 95 & 34 & 45 & 11 & 6 \\
2 & 36 & 46 & 20 & 30 & 16 & 10 & 8 \\
3 & 29 & 41 & 35 & 26 & 25 & 11 & 4 \\
Rata-rata & 34 & 41 & 50 & 30 & 29 & 11 & 6 \\
\hline
\end{tabular}

Berdasarkan tabel 5.2 dapat diketahui bahwa rata-rata jumlah angka kuman pada usap alat sekelompok piring sesudah diberikan perlakuan desinfeksi menggunakan larutan serbuk daun jeruk purut (Citrus hystrix. DC) dengan variasi konsentrasi $0 \mathrm{gr} / \mathrm{L}, 50 \mathrm{gr} / \mathrm{L}, 60 \mathrm{gr} / \mathrm{L}$, $70 \mathrm{gr} / \mathrm{L}, 80 \mathrm{gr} / \mathrm{L}, 90 \mathrm{gr} / \mathrm{L}$ dan $100 \mathrm{gr} / \mathrm{L}$ berkisar antara $50-6 \mathrm{koloni} / \mathrm{cm}^{2}$.

\section{Penurunan Angka Kuman}

Berdasarkan tabel 1 dan 2 dapat diketahui bahwa rata-rata penurunan jumlah angka kuman pada tiap perlakuan desinfeksi dengan variasi konsentrasi larutan serbuk daun jeruk purut (Citrus hystrix. DC), yang dapat dilihat pada tabel 3. 
Tabel 3. Rata-rata Penurunan Jumlah Angka Kuman (koloni/ $\left.\mathrm{cm}^{2}\right)$ pada Tiap Perlakuan Desinfeksi Menggunakan Larutan Daun Jeruk Purut (Citrus hystrix. DC)

\begin{tabular}{ccccc}
\hline Konsentrasi & \multicolumn{2}{c}{$\begin{array}{c}\text { Rata-rata Angka Kuman } \\
\text { (koloni/cm²) }\end{array}$} & $\begin{array}{c}\text { Penurunan } \\
(\mathrm{N})\end{array}$ & $\begin{array}{c}\text { Prosentase } \\
(\%)\end{array}$ \\
& Sebelum & Sesudah & & \\
\hline $0 \mathrm{gr} / \mathrm{L}$ & 44 & 34 & 10 & 23 \\
$50 \mathrm{gr} / \mathrm{L}$ & 56 & 41 & 15 & 27 \\
$60 \mathrm{gr} / \mathrm{L}$ & 72 & 50 & 22 & 38 \\
$70 \mathrm{gr} / \mathrm{L}$ & 64 & 30 & 34 & 53 \\
$80 \mathrm{gr} / \mathrm{L}$ & 73 & 29 & 44 & 62 \\
$90 \mathrm{gr} / \mathrm{L}$ & 58 & 11 & 47 & 81 \\
$100 \mathrm{gr} / \mathrm{L}$ & 55 & 6 & 49 & 89 \\
\hline
\end{tabular}

Berdasarkan tabel 3 dapat dilihat bahwa semakin besar konsentrasi larutan serbuk daun jeruk purut (Citrus hystrix. DC) yang digunakan, menunjukkan rata-rata jumlah angka kuman sesudah perlakuan desinfeksi lebih rendah dari rata-rata jumlah angka kuman sebelum perlakuan desinfeksi.
Secara statistik perbedaan ratarata jumlah angka kuman sebelum dan sesudah diberi perlakuan desinfeksi menggunakan larutan serbuk daun jeruk purut (Citrus hystrix. DC) dapat dibuktikan dengan uji Paired T-test atau uji sampel berpasangan pada tingkat kesalahan $(\alpha) 5 \%$, adapun hasil uji statistik dapat dilihat pada tabel 4 .

Tabel 4. Hasil Uji Statistik Paired T-test pada Tiap Konsentrasi Larutan Serbuk Daun Jeruk Purut (Citrus hystrix. DC)

\begin{tabular}{|c|c|c|c|}
\hline Konsentrasi & Nilai p (p-value) & Kesimpulan & Keterangan \\
\hline $0 \mathrm{gr} / \mathrm{L}$ & 0,031 & $\mathrm{H}_{0}$ ditolak & $\begin{array}{l}\text { Ada perbedaan rata-rata } \\
\text { angka kuman }\end{array}$ \\
\hline $50 \mathrm{gr} / \mathrm{L}$ & 0,044 & $\mathrm{H}_{0}$ ditolak & $\begin{array}{l}\text { Ada perbedaan rata-rata } \\
\text { angka kuman }\end{array}$ \\
\hline $60 \mathrm{gr} / \mathrm{L}$ & 0,032 & $\mathrm{H}_{0}$ ditolak & $\begin{array}{l}\text { Ada perbedaan rata-rata } \\
\text { angka kuman }\end{array}$ \\
\hline $70 \mathrm{gr} / \mathrm{L}$ & 0,009 & $\mathrm{H}_{0}$ ditolak & $\begin{array}{l}\text { Ada perbedaan rata-rata } \\
\text { angka kuman }\end{array}$ \\
\hline $80 \mathrm{gr} / \mathrm{L}$ & 0,015 & $\mathrm{H}_{0}$ ditolak & $\begin{array}{l}\text { Ada perbedaan rata-rata } \\
\text { angka kuman }\end{array}$ \\
\hline $90 \mathrm{gr} / \mathrm{L}$ & 0,023 & $\mathrm{H}_{0}$ ditolak & $\begin{array}{l}\text { Ada perbedaan rata-rata } \\
\text { angka kuman }\end{array}$ \\
\hline $100 \mathrm{gr} / \mathrm{L}$ & 0,000 & $\mathrm{H}_{0}$ ditolak & $\begin{array}{l}\text { Ada perbedaan rata-rata } \\
\text { angka kuman }\end{array}$ \\
\hline
\end{tabular}

Berdasarkan tabel 4 dapat diketahui bahwa secara statistik ada perbedaan rata-rata jumlah angka kuman pada piring sebelum dan sesudah diberikan perlakuan menggunakan larutan serbuk daun jeruk purut (Citrus hystrix. DC) untuk setiap konsentrasi yang digunakan.

Kemudian untuk hasil prosentase penurunan jumlah angka kuman setelah dilakukan desinfeksi dengan larutan serbuk daun jeruk purut (Citrus hystrix. DC) pada variasi 
konsentrasi $0 \mathrm{gr} / \mathrm{L}, 50 \mathrm{gr} / \mathrm{L}, 60 \mathrm{gr} / \mathrm{L}$, $70 \mathrm{gr} / \mathrm{L}, 80 \mathrm{gr} / \mathrm{L}, 90 \mathrm{gr} / \mathrm{L}$ dan $100 \mathrm{gr} / \mathrm{L}$ berkisar antara $23-89 \%$.

4. Hubungan variasi konsentrasi larutan serbuk daun jeruk purut (Citrus hystrix. DC) dengan jumlah angka kuman

Pada penelitian ini untuk mengetahui keeratan hubungan dan arah hubungan antara variasi konsentrasi larutan serbuk daun jeruk purut dengan penurunan angka kuman pada sampel, digunakan analisis progaram komputer yaitu uji korelasi.

Adapun hasil uji statistik korelasi variasi konsentrasi larutan serbuk daun jeruk purut dengan penurunan jumlah angka kuman dapat dilihat pada tabel 5 .

Tabel 5. Hasil Uji Korelasi Variasi Konsentrasi Larutan Serbuk Daun Jeruk Purut dengan Penurunan Jumlah Angka Kuman

\begin{tabular}{cccc}
\hline $\begin{array}{c}\text { Nilai Korelasi } \\
(\mathrm{r})\end{array}$ & $\begin{array}{c}\text { Nilai } \mathrm{p} \\
(\mathrm{p} \text {-value })\end{array}$ & Kesimpulan & Keterangan \\
\hline 0,991 & 0,000 & $\mathrm{H}_{0}$ ditolak & Ada hubungan \\
\hline
\end{tabular}

Berdasarkan tabel 5 dapat diketahui bahwa hasil uji statistik korelasi menunjukkan ada hubungan variasi konsentrasi larutan serbuk daun jeruk purut (Citrus hystrix. DC) dengan penurunan jumlah angka kuman.
Untuk mengetahui bentuk hubungan variasi konsentrasi larutan serbuk daun jeruk purut (Citrus hystrix. $D C$ ) dengan penurunan jumlah angka kuman, maka digunakan persamaan regresi linear degan hasil uji sebagai berikut :

Tabel 6. Hasil Uji Statistik Persamaan Regresi Linear

\begin{tabular}{cccc}
\hline R-Square & $\begin{array}{c}\text { Constant } \\
(\mathrm{a})\end{array}$ & $\begin{array}{c}\text { Coefficients } \\
(\mathrm{b})\end{array}$ & $\begin{array}{c}\text { Nilai p } \\
\text { (p-value) }\end{array}$ \\
\hline 0,982 & 6,143 & 11,786 & 0,000 \\
\hline
\end{tabular}

Berdasarkan tabel 6 dapat disimpulkan bahwa model regresi sederhana cocok dengan data yang ada dan ada hubungan linear antara variasi konsentrasi larutan serbuk daun jeruk purut (Citrus hystrix. DC) dengan penurunan jumlah angka kuman. Adapun model persamaan garis regresi variasi konsentrasi larutan serbuk daun jeruk purut dengan penurunan jumlah angka kuman adalah $y=6,143+11,786 x$.

Berdasarkan hasil pemeriksaan usap alat pada 42 sampel sekelompok piring di warung makan Warjok yang telah melewati tahapan pencucian piring seperti : scraping, flushing, washing dan rinsing, diketahui bahwa rata-rata jumlah angka kuman sebelum diberikan perlakuan desinfeksi dengan menggunakan variasi konsentrasi larutan serbuk daun jeruk purut (Citrus hystrix. DC) 0 $\mathrm{gr} / \mathrm{L}, 50 \mathrm{gr} / \mathrm{L}, 60 \mathrm{gr} / \mathrm{L}, 70 \mathrm{gr} / \mathrm{L}, 80 \mathrm{gr} / \mathrm{L}$, $90 \mathrm{gr} / \mathrm{L}$ dan $100 \mathrm{gr} / \mathrm{L}$ berkisar antara 44 $73 \mathrm{koloni} / \mathrm{cm}^{2}$.

Bila dibandingkan dengan Keputusan Menteri Kesehatan Nomor 1098 tahun 2003 tentang Persyaratan Hygiene Sanitasi Rumah Makan dan Restoran, rata-rata jumlah angka kuman pada sekelompok piring sebelum diberi perlakuan dengan variasi konsentrasi larutan serbuk daun jeruk purut (Citrus hystrix. $D C$ ) telah memenuhi standar kebersihan peralatan makan yaitu 100 koloni $/ \mathrm{cm}^{2}$. Hal ini dikarenakan pada warung makan Warjok menggunakan tiga bak pembilas dalam proses pencucian piring dan sabun cuci piring yang memiliki daya anti bakteri serta penggunaan air PDAM sebagai sarana air pencucian piring yang mengandung khlorin sehingga jumlah angka kuman 
yang diperkirakan pada piring telah berkurang.

Setelah dilakukan proses desinfeksi yaitu perlakuan perendaman dengan menggunakan variasi konsentrasi larutan serbuk daun jeruk purut (Citrus hystrix. $D C)$ yaitu $50 \mathrm{gr} / \mathrm{L}, 60 \mathrm{gr} / \mathrm{L}, 70 \mathrm{gr} / \mathrm{L}, 80$ gr/L, 90 gr/L dan 100 gr/L serta kontrol yang menggunakan air mineral dengan waktu kontak 3 menit, diperoleh hasil rata-rata jumlah angka kuman pada sampel usap alat piring berkisar antara 50 - 6 koloni/ $\mathrm{cm}^{2}$ dan hasil tersebut lebih rendah dibandingkan dengan rata-rata jumlah angka kuman pada piring sebelum diberikan perlakuan. Hal ini karena pada daun jeruk purut (Citrus hystrix. DC) memiliki kandungan senyawa kimia polifenol, minyak atsiri, flavonoid, tanin dan alkaloid yang berfungsi untuk mencegah pertumbuhan bakteri dengan cara mengganggu kestabilan membran sel dan metabolisme energi bakteri sehingga berdampak pada kematian sel bakteri[6].

Berdasarkan hasil uji Paired T-test atau uji beda sampel berpasangan pada sampel usap alat piring sebelum dan sesudah diberikan perlakuan perendaman menggunakan larutan serbuk daun jeruk purut (Citrus hystrix. DC), terbukti bahwa secara statistik ada perbedaan rata-rata jumlah angka kuman sebelum dan sesudah diberikan perlakuan desinfeksi dengan variasi konsentrasi larutan serbuk daun jeruk purut (Citrus hystrix. DC) pada tingkat kesalahan alfa 5\% (nilai $\mathrm{p}<$ nilai $\alpha$ ), dengan prosentase penurunan jumlah angka kuman yang paling baik dalam menurunkan angka kuman setelah dilakukan desinfeksi dengan larutan serbuk daun jeruk purut (Citrus hystrix. $D C$ ) adalah pada konsentrasi $100 \mathrm{gr} / \mathrm{L}$ (89\%).

Kemudian untuk keeratan hubungan dan arah hubungan antara variasi konsentrasi larutan serbuk daun jeruk purut (Citrus hystrix. DC) dengan penurunan jumlah angka kuman yang telah di uji menggunakan uji korelasi, terbukti bahwa secara statistik ada hubungan variasi konsentrasi larutan serbuk daun jeruk purut dengan penurunan jumlah angka kuman yang menunjukkan hubungan sangat kuat dan berpola positif yang berarti semakin tinggi konsentrasi larutan serbuk daun jeruk purutnya maka semakin besar penurunan jumlah angka kumannya (nilai $p=0,000<$ nilai $\alpha=0,05$ ).

Untuk persamaan regresi dengan nilai koefisien determinan (R-Square) $=0,982$, artinya persamaan garis regresi yang diperoleh adalah 98,2\% yang dapat ditafsirkan bahwa variabel bebas variasi konsentrasi larutan serbuk daun jeruk purut memiliki pengaruh $98,2 \%$ terhadap variabel penurunan jumlah angka kuman dan 1,8\% lainnya dipengaruhi oleh faktorfaktor lain diluar variabel variasi konsentrasi larutan serbuk daun jeruk purut. Adapun hasil persamaan garis regresi sederhana yang diperoleh adalah y $=6,143+11,786 \mathrm{x}$ dengan nilai $\mathrm{b}=11,786$ yang berarti bahwa variabel penurunan jumlah angka kuman akan bertambah sebesar 11,786 bila konsentrasi larutan serbuk daun jeruk purut bertambah setiap $1 \mathrm{gr} / \mathrm{L}$.

\section{KESIMPULAN DAN SARAN}

Perkiraan jumlah angka kuman pada sekelompok piring sebelum diberikan perlakuan menggunakan larutan serbuk daun jeruk purut (Citrus hystrix. DC) berkisar antara 38 - $125 \mathrm{koloni} / \mathrm{cm}^{2}$.

Perkiraan jumlah angka kuman pada sekelompok piring sesudah diberikan perlakuan menggunakan larutan sebuk daun jeruk purut (Citrus hystrix. DC) dengan variasi konsentrasi $50 \mathrm{gr} / \mathrm{L}, 60$ $\mathrm{gr} / \mathrm{L}, 70 \mathrm{gr} / \mathrm{L}, 80 \mathrm{gr} / \mathrm{L}, 90 \mathrm{gr} / \mathrm{L}$ dan 100 $\mathrm{gr} / \mathrm{L}$ berkisar antara $95-4 \mathrm{koloni} / \mathrm{cm}^{2}$.

Prosentase penurunan perkiraan jumlah angka kuman pada sekelompok piring sebelum dan sesudah diberikan perlakuan desinfeksi menggunakan larutan serbuk daun jeruk purut (Citrus hystrix. DC) dengan variasi konsentrasi 50 $\mathrm{gr} / \mathrm{L}, 60 \mathrm{gr} / \mathrm{L}, 70 \mathrm{gr} / \mathrm{L}, 80 \mathrm{gr} / \mathrm{L}, 90 \mathrm{gr} / \mathrm{L}$ dan $100 \mathrm{gr} / \mathrm{L}$ berkisar antara $23-89 \%$.

Ada hubungan variasi konsentrasi larutan serbuk daun jeruk purut (Citrus hystrix. $D C$ ) dengan perkiraan jumlah angka kuman pada piring yang 
menunjukkan hubungan sangat kuat dan berpola positif yang berarti semakin tinggi konsentrasi larutan sebuk daun jeruk purutnya maka semakin besar penurunan jumlah angka kumannya.

Dapat disarankan penggunaan desinfektan alami seperti daun jeruk purut dapat digunakan sebagai pengganti bahan kimia sebagai bahan desinfeksi untuk mengurangi adanya limbah cair yang dapat menimbulkan pencemaran lingkungan akibat penggunaan bahan kimia, namun dengan syarat untuk kondisi penerapan tahapan proses pencucian peralatan makan yang sama dengan lokasi penelitian.

\section{KEPUSTAKAAN}

1. Kementrian Pendidikan dan Kebudayaan, 2013. Keamanan Pangan. Jakarta: p: 24

2. George, J. Benwart, 1979. Basic Food Microbiology. Avi Publishing Company, Inc, Wesport, Connecticut.

3. Sulistiyani, Ulfa Nurullita, Dina Dwi Nuryani, 2004. Perbedaan Jumlah Mikroba pada Alat Makan Sebelum dan Sesudah Dicuci dengan Daun Jeruk Purut (Citrus Histrix. DC). Jurnal Kesehatan Masyarakat Indonesia, Semarang. Vol 1. No. 2. pp : 59-63.

4. Munawaroh, S. , Handayani, Astuti P, 2010. Ekstraksi Minyak Daun Jeruk Purut (Citrus hystrix D.C.) dengan Pelarut Etanol dan N-Heksana. JurnalKompetensi Teknik. 2(1) pp : 7378.

5. Miftahendarwati, 2014. Efek antibakteri ekstrak daun jeruk purut (Citrus hystrix) terhadap bakteri Streptococcus mutans(in vitro). Skripsi Fakultas Kedokteran Gigi, Universitas Hasanuddin : Makassar.

6. Chismirina S, Poppy A, Nopi YF, 2011. Efek Ekstrak Buah Jamblang terhadap Pertumbuhan Streptococcus mutans sebagai Penyabab Utama Karies. Dentika ; 16(2): pp: 144-8. 